\title{
РЕКРЕАЦИОННО-ЭКОЛОГИЧЕСКИЕ АСПЕКТЫ ОСВОЕНИЯ ЛИВАДИЙСКОГО ХРЕБТА
}

\author{
Леусов А.Э., Малюгин А.В. \\ Дальневосточный федеральный университет, Владивосток \\ Leusov.andrei@mail.ru,malyugin.av@dvfu.ru
}

Аннотация. В статье рассматриваются аспекты рекреационного освоения Ливадийского хребта в контексте его экологического состояния. Ливадийский хребет является популярным туристическим направлением Приморского края. В определенные дни на горе Ливадийская, также известной как Пидан, или на пути к Смольным водопадам можно насчитать свыше тысячи человек. Пиковые значения обычно приходятся на вторую половину сентября - начало октября. У подножия Литовки (второе название - Фалаза) выстроено множество баз отдыха вблизи горнолыжной трассы, позволяющих принять значительное количество туристов. По результатам многолетних наблюдений отмечается устойчивая тенденция к росту потока рекреантов. Западный тысячник Лысый Дед также может привлечь туристов как минимум обломками самолетов, разбившихся на его склонах, но слабая транспортная доступность ограничивает приток туристов. Рост потока отдыхающих при слаборазвитой туристской инфраструктуре оказывают неблагоприятное воздействие на ландшафты хребта. Замусоривание, разрушение почвенного и вытаптывание растительного покровов - лишь часть существующих проблем. Более существенной проблемой являются пожары, приходящие преимущественно с прилегающих сельскохозяйственных угодий. Так, с выгоревшей микробиотой в привершинной части г. Литовка в 2019 году явно потеряла в эстетичности и пейзажном разнообразии. Решению существующих и предупреждению развития новых проблем может помочь создание Южно-Приморского (или Ливадийского) национального парка. Этот вопрос разрабатывается разными авторами с 80-х годов прошлого века. Предложения охраны территории включали различные формы - от охраны отдельных вершин до создания национального парка. Именно последнее, по мнению авторов данной работы, поможет лучше всего сохранить природу хребта, оставляя возможность жителям и гостям края получить удовольствие от отдыха на его территории. Экологическую нагрузку также позволит снизить создание и оборудование экологической тропы. Основываясь на примерах российской и зарубежной практики, предлагается маршрут под названием «Большая Ливадийская тропа» - длительностью в несколько дней с посещением наиболее интересных и доступных мест хребта. Широкий обзор с вершин, скалы-останцы, водопады, разнообразие пейзажей, уникальная флора и фауна, а также наилучшая среди горных территорий края транспортная доступность - все это делает Ливадийский хребет перспективным объектом для дальнейшего развития туризма, но уже сейчас настойчиво требует более бережного отношении к окружающей среде.

Ключевые слова: Ливадийский хребет, Ливадийская, Литовка, Скалистая, Лысый Дед, национальный парк, туризм, экологические проблемы, экологическая тропа 


\title{
RECREATIONAL AND ECOLOGICAL ASPECTS OF DEVELOPMENT OF THE LIVADIJSKIJ RIDGE
}

\author{
Leusov A.E., Malugin A.V. \\ Far Eastern Federal University, Vladivostok
}

\begin{abstract}
Annotation. The article presents the issues of recreational development and ecological conditions of the Livadijskij Ridge. Livadijskij is a popular tourist destination of Primorskij Krai. On the mountain Livadijskaya also known as Pidan on certain days you can count more than a thousand people. At the foot of Litovka (second name is Falaza) built many recreation centers, allowing to take a significant number of tourists. According to the results of long-term observations, there is a tendency to increase the flow of people. The growth of the flow of tourists with underdeveloped tourist infrastructure have an adverse impact on the landscapes of the ridge. Littering and destruction of soil are only part of existing problems. A more significant problem is fires coming mainly from adjacent agricultural land. The creation of national park Livadijskij can help to solve existing problems and prevent the development of new ones. This question has been researched by different authors since 80 s of the last century. Proposals for the protection of territory included various forms. According to the authors of this article, the creation of a national park will be the best option. It will help to preserve the nature of the territories, leaving the opportunity for residents and guests of the region to enjoy the rest on the ridge. The ecological load will also be reduced by the creation and equipment of the ecological trail. Based on the examples of Russian and foreign practice, we propose a route called "the Great Livadijskij trail". A wide view from the peaks, waterfalls, unique flora and fauna and a variety of landscapes all this makes the Livadijskij ridge a promising object for further development of tourism, but it also requires a more careful attitude to the environment.
\end{abstract}

Key words: Livadijskij ridge, Livadijskaja, Litovka, Skalistaja, Lisij Ded, national park, tourism, ecological problem, ecological trail

Развитие туристско-рекреационного комплекса - приоритетное направление экономики Приморского края и России в целом. В концепции федеральной целевой программы «Развитие внутреннего и въездного туризма в Российской Федерации (2019-2025 годы)» указывается, что особое внимание будет уделено внутреннему туризму, который рассматривается как одна из задач импортозамещения. За 2018 год общий туристский поток в Приморский край уже превысил 4,5 млн человек, из которых 651,8 тыс. были иностранцами [7]. Положительная динамика роста турпотока в ближайшие годы, предположительно, сохранится.

Территория края больше всего подходит для спортивного и экологического туризма, но преобладающая доля гостей устремляется в летний период к морским пляжам, формируя пиковые значения при- 
бытий в июле-августе, рассматривая внутренние районы преимущественно как транзитные. Одним из вариантов снизить экологическую нагрузку на побережье может послужить переориентация туристов на объекты внутри края, в частности в горные районы. Если не рассматривать низкие Чёрные горы в пограничной зоне, то наилучшей транспортной, а значит и туристской, доступностью будет отличаться Ливадийский хребет с наивысшими в южном Приморье вершинами.

Ливадийский хребет является самым популярным среди горных территорий у жителей Приморского края. Этому способствует наличие с севера железной дороги с пригородными электропоездами и автомобильных дорог по всему периметру. С южной стороны возможно прибытие на маршрут междугородними автобусами. Такая доступность привлекает туристов в походы выходного дня со всего юга края, чем успешно пользуются туристские организации, обеспечивающие транспортную доставку и экскурсионное обслуживание. Интерес к хребту есть и у иностранных туристов [11], но их доля крайне мала.

Среди вершин хребта самой посещаемой является гора Ливадийская (в народе именуемая Пидан). Основных маршрутов подъема два (оба со стороны Лукьяновки), но изредка возможен подход туристов со стороны горы Лысый Дед и со стороны Новолитовска. Так, если в 2002 году в конце сентября - начале октября в выходные на гору поднималось не более 170 человек в день, то в 2013-м суточная посещаемость превысила 1000 человек, а в 2017 году достигла 1700 [12]. В целом наблюдается общая тенденция к росту. Конечно, такие показатели возможны при наличии теплой погоды с ясным небом. По мере усиления осеннего выхолаживания поток быстро падает. К примеру, уже 6 октября 2018 года на гору совершили восхождение всего около 800 человек. В этот день был сильный ветер, пасмурное небо, без теплой одежды туристы быстро замерзали.

Гора Литовка (Фалаза) - вторая из трех главных вершин Ливадийского хребта. Здесь три основных маршрута подъема, изредка заходят туристы со стороны Ливадийской, штурмуя траверс. Несмотря на свою внушительную высоту в 1279 метров, гора привлекает множество неподготовленных туристов. Не в последнюю очередь потому, что у подножья, преимущественно в Анисимовке, выстроено множество турбаз с удобствами, где можно остаться на ночь (более 820 койко-мест, включая несколько баз в Лукьяновке). Однако эти базы летом обычно простаивают пустыми в ожидании горнолыжного сезона 
зимой. Здесь проводятся мультиспортивная гонка «Falaza Challenge» и соревнования по горному бегу «Январские обгонялки», привлекающие спортсменов из Приморья и соседних регионов.

Летом вершину Литовки посещает меньшее количество рекреантов, чем Ливадийскую. Но их все еще большое количество (более 100 человек в пиковые дни [13]). У расположенных у подножья Смольных водопадов в силу меньшей сложности посещения турпоток выше почти в два раза в аналогичные даты. В экологическом плане вершина горы Литовка выглядела ещё недавно лучше Ливадийской. Однако пожар в мае 2019 года полностью уничтожил растительность в привершинной части с юго-запада [2]. Особенно сильно пострадали заросли микробиоты (рис. 1). Огонь прошел по территории между вершиной и ручьем Смольный - одним из самых популярных вариантов подъема у туристов. Причиной могли быть как брошенный окурок, так и непотушенное кострище, которых так много в привершинной части.

Третья по популярности вершина рассматриваемой территории имеет статус памятника природы - это гора Скалистая (известна

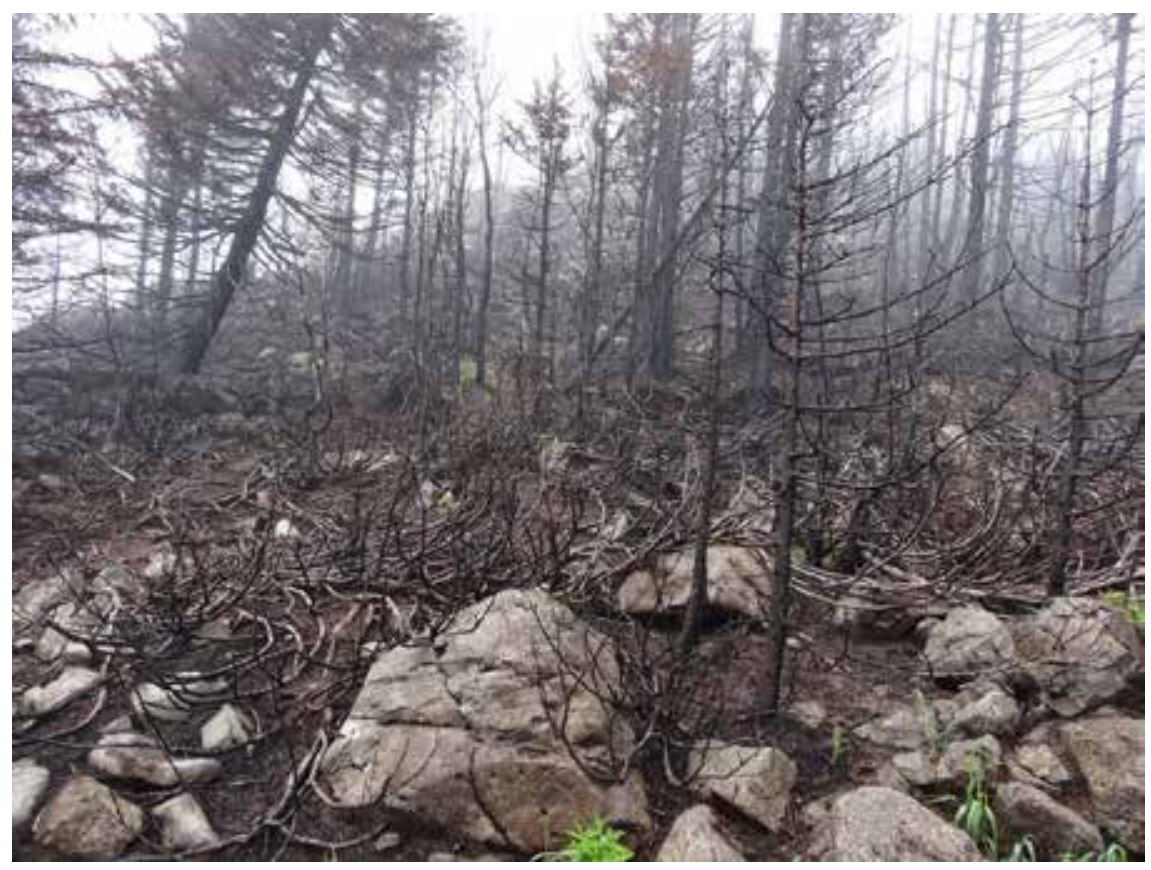

Рис. 1. Последствия пожара на вершине Литовки (фото А.В. Малюгина от 26.06.2019) 
также как Читинза). Количество туристов в пиковые дни обычно не превышает нескольких десятков человек. Интерес вызывает не только сама вершина, с которой есть обширная панорама на долину реки Партизанская, но и сам подъем, изобилующий скалами. Весной на подъеме постоянно открываются склоны, покрытые цветущим рододендроном, а осенью кружит огненно-багряный листопад среди зеленых пихт и кедров. Количество троп к вершине здесь максимально, выделяется не менее 6 вариантов подъёма. Самая вытоптанная идет со стороны переезда Красноармейский, если пройти через поселок Ручьи. На вершине ещё сохранилась древесная растительность, но повсеместно раскиданы кострища. Это самая удобная вершина для установки палаток, которые защищены здесь от сильных ветров кронами деревьев, поэтому здесь можно наблюдать множество параллельных тропинок от площадки к площадке. От более быстрой деградации растительности вершину спасает отсутствие комфортного подъезда к подножью, есть только грунтовые дороги. Гора требует большей физической подготовки от туристов, так как чаще всего её штурмуют с расчетом на ночёвку и несут необходимое для этого снаряжение, и потому ожидать взрывного роста турпотока не приходится.

Гора Лысый Дед - не часто посещаемая туристами вершина Приморья (счет идет на единицы в день) по причине плохой транспортной доступности (только личный автотранспорт или пешком). Однако она заслуживает большего. Подъем в гору по тропе плавный без длительных крутых участков, тропа узкая, не разбитая, что говорит о редких посетителях. Вершина действительно лишена древесной растительности, с неё открывается обширная панорама. Однако интерес к вершине в другом, здесь в 1950-е годы прошлого века с перерывом в несколько лет на склонах разбились три военных самолета. Обломки одного из них расположены на тропе вблизи вершины. Последствия пожаров по итогу их крушений практически не заметны, растительность повсеместно восстановилась.

Гора Смольная практически не посещается туристами. Вершина полностью покрыта лесом. Обзора с неё нет совершенно никакого. Достопримечательностей нет. Интереса, кроме спортивного, не вызывает. Близко к вершине подходит старая лесовозная дорога.

Увеличивающееся из года в год количество туристов создает определенные проблемы. Разрушается почвенный покров, вырождается растительность, происходит замусоривание, пожары становятся 
все чаще. Развешивание тряпочек на удачу по пути следования, кострища, прочий мусор. Помочь в регулировании рекреационных нагрузок, охране данных территорий и создании более организованных туристических потоков сможет создание Южно-Приморского (или Ливадийского) национального парка.

Вопрос создания охраняемой территории, включающей территорию Ливадийского хребта, поднимался уже давно. Предложения о создании здесь такого рода объектов разрабатываются разными авторами с 1981 г. Отмечается, что спектр предложений был весьма разным - от памятников природы на отдельных вершинах и местообитаний конкретных видов до проектов национального парка [1, 5-6]. В литературе конца XX века указывалось что уже разработана проектная документация и она находится в стадии утверждения [10]. Но и к настоящему времени вопрос о создании парка все еще висит в воздухе, хотя и наметились определенные подвижки. Как сообщил руководитель краевого департамента по охране, контролю и регулированию использования объектов животного мира Дмитрий Панкратов: «...В следующем году приступим к организации национального парка «Южно-Приморский», территория под который уже зарезервирована в генеральном плане» [4]. Отметим, что хоть в интервью и говорится о создании национального парка, по распоряжению №26-р департамента земельных и имущественных отношений Приморского края «о резервировании земель под особо охраняемые природные территории регионального значения» [3] земли зарезервированы под природный парк. Авторы данной работы считают более целесообразным присвоение данной территории именно статуса национального парка, что обеспечивает федеральную поддержку и контроль. Также предлагается включить в его состав всю горную часть Ливадийского хребта между вершинами Лысый Дед - Скалистая, а не ограничиваться отдельным участком северного макросклона Ливадийского хребта между Лукьяновкой и Анисимовкой. Также стоит провести масштабную работу по восстановлению продуктивности местных лесов, проведя посадку саженцев кедра (по примеру национального парка «Земля леопарда»).

Идея как национального, так и природного парка позволяет вести в его пределах ограниченную хозяйственную деятельность, прибыль от которой можно потратить на организационные и природоохранные нужды. К примеру, организовать и обустроить экологические тропы на 
месте уже протоптанных маршрутов, чтобы избежать появления новых. Это позволит нормализовать экологическую нагрузку (например, как на о. Петрова в Лазовском заповеднике). Конечно, масштабы работ не сопоставимы, но предлагается начать с самых массовых участков обустроить кольцевой маршрут по линии Лукьяновка - гора Ливадийская - гора Литовка - Анисимовка. В данный момент тропа между горами Ливадийская и Литовка практически отсутствует. Этот трек при условии подготовленной тропы при хорошей физической подготовке и налегке можно пройти за световой день. Подобные работы по созданию троп проводились Ю.И. Берсеневым на Милоградовке, также работают волонтеры на Байкале. К расчистке и обустройству троп можно привлечь бойцов из студенческого отряда «Тигр».

По Ливадийскому хребту имеется 2 эталонных пешеходных маршрута первой категории сложности [8], прохождение которых не стоит запрещать при организации национального парка. Наоборот, на базе одного из них можно создать «Большую Ливадийскую тропу» (рис. 2) - оборудованный маршрут для трекинга длительностью в несколько дней с местами под стоянки или даже с созданием кемпингов. Для привлечения туристов стоит отметить интересные для посещения места, например, на информационном стенде в начале маршрута и у самих мест. Можно предположить, исходя из климатических особенностей территории, что маршрут будет пользоваться большей популярностью в два временных отрезка: в первой половине мая (между таянием снега в привершинной части и появлением кровососущих насекомых) и в конце сентября - начале октября (завершилось прохождение тайфунов, осенний листопад). Стоит понимать, что помимо обустройства тропы, большой проблемой является отсутствие достаточного количества мест, где можно пополнить запасы воды по пути, и её надо будет решить.

Маршрут предлагается начинать в селе Лукьяновка по причине транспортной доступности. Линия выбрана с учетом опыта прохождения. Движение на Ливадийскую предлагается со стороны Энцефалитного ручья (точка Б на рис. 2), склон здесь не столь крутой, как со стороны Ойры, где сегодня наблюдается самый массовый подъем. Большую сложность будет вызывать прохождение участка по линии В-Г. Ноги постоянно будут заплетаться в зарослях заманихи и актинидии, потому без расчистки тропы неподготовленному туристу здесь делать нечего. Дополнительную сложность вызовет спуск с Литов- 


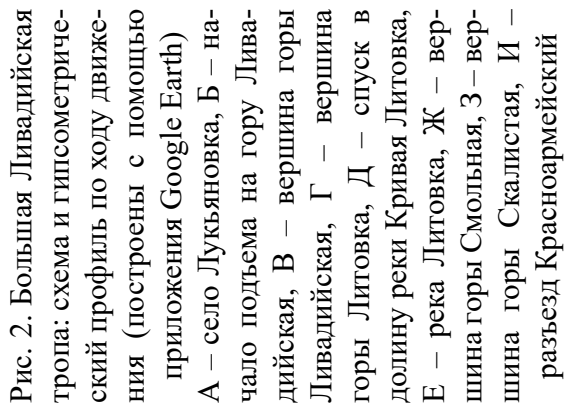
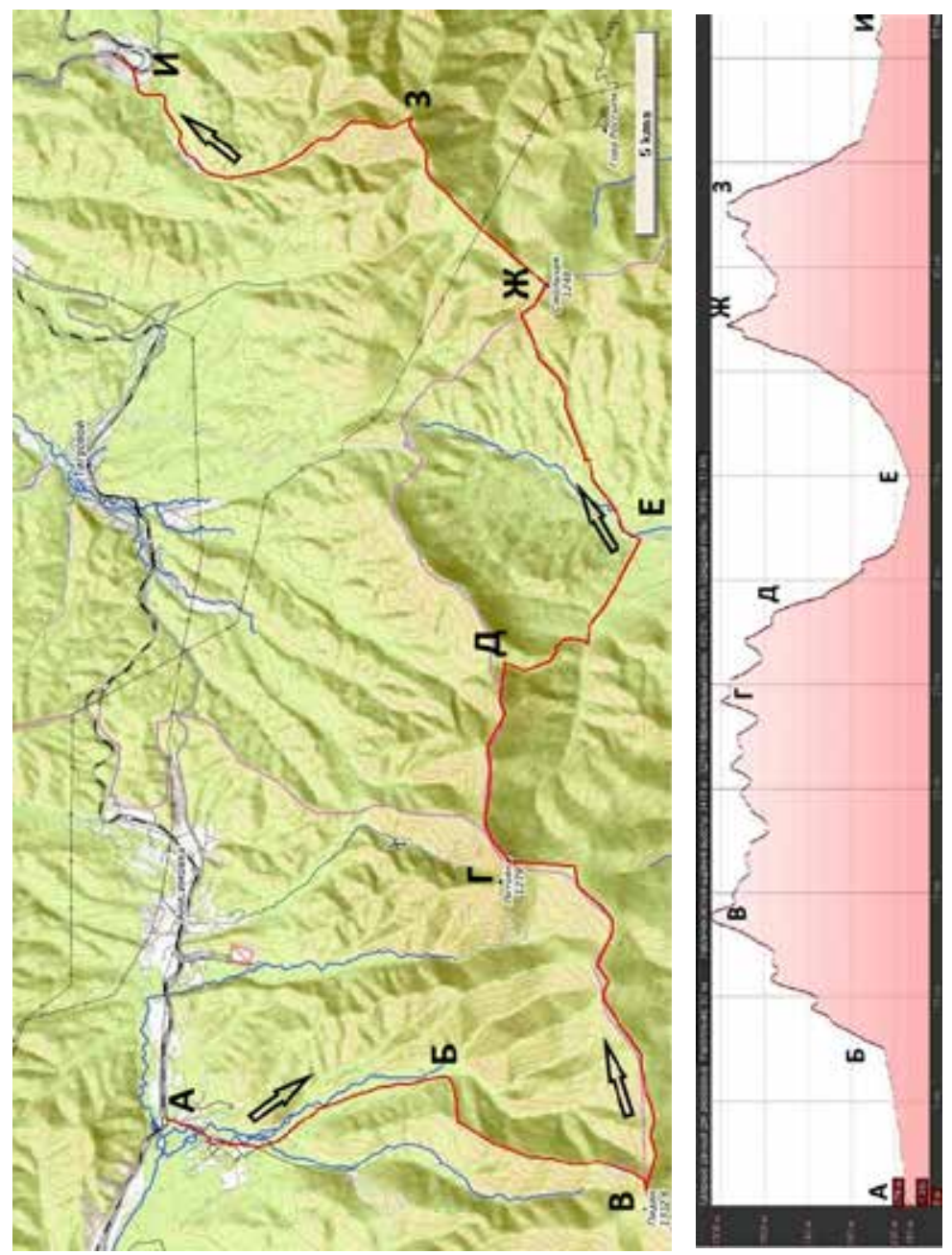
ки. Предлагается начало спуска в точке Д. Это очень крутой склон, но здесь наблюдается лесовозная дорога, которая упростит задачу. Остальные участки больших проблем не вызывают. При наличии достаточной физической подготовки нитку маршрута можно изменить и произвести спуск со Скалистой не на Красноармейский, а на Партизанск через водопад реки Каменки (другие названия - Арсеевский, а также - Берендей). Водопад интересен только в периоды обильного снеготаяния и после сильных дождей.

Особый интерес может вызвать факт, что три вершины на маршруте (Ливадийская, Литовка, Скалистая) входят в список «Приморского Барса» [9] - почетного знака, учрежденного Приморской Федерацией спортивного туризма. Он присваивается после подтверждения факта восхождения путем предоставления фотографий претендента у контрольных точек на каждой вершине.

\section{По результатам работы были сделаны следующие выводы:}

1. Ливадийский хребет в силу транспортной доступности и близости к населенным пунктам и дорогам испытывает избыточную антропогенную нагрузку, постоянно подвергается воздействию пожаров. Хребет испытывается максимальную рекреационную нагрузку среди горных систем Приморского края. В связи с тем, что не проводится никаких мероприятий по созданию инфраструктуры, позволяющих регулировать рекреационную нагрузку, последняя растет пропорционально росту посещаемости.

2. Максимальная рекреационная нагрузка приходится на северные склоны гор Ливадийская и Литовка. Предлагается частично перенаправить туристские потоки на соседние вершины Лысый Дед и Скалистая. Но для этого надо решить вопрос с транспортной доступностью этих участков.

3. Предлагается при отсутствии должного контроля за состоянием природной среды Ливадийского хребта взять его склоны под охрану в виде организации национального парка с расширением охраняемой территории сверх зарезервированных угодий на всю горную часть хребта, включая массив горы Скалистая.

4. Используя положительный опыт работы по организации экологических троп Лазовского и Сихотэ-Алинского заповедников, а также по повышению продуктивности лесов в национальном парке «Земля леопарда», необходимо провести аналогичные работы на территории 
предлагаемого к организации Ливадийского национального парка. Экологические тропы стоит оборудовать в пределах уже существующих маршрутов.

5. Для привлечения туристов предлагается создать новый туристский продукт - Большую Ливадийскую тропу, которая должна быть доступна для прохождения не только спортивным туристам, но и людям с меньшими физическими возможностями. При решении вопроса с транспортной доступностью до подножья г. Лысый Дед целесообразно сделать начало тропы с Моленного Мыса через данную вершину.

Научные руководители: профессор ДВФУ, д.г.н. П.Ф. Бровко, доиент ДВФУ, к.г.н. Сазыкин А.М.

\section{Литература}

1. Берсенев Ю.И. Особо охраняемые природные территории Приморского края: существующие и проектируемые. Владивосток: Изд-во Дальневост. федерал. ун-та, 2017. $202 \mathrm{c}$.

2. Горит и очень сильно: жителей Приморья беспокоит ситуация на Фалазе. [Электронный ресурс] // PrimaMedia.ru. - Режим доступа: https://primamedia.ru/ news/816223/ (дата обращения: 27.05.2019).

3. Департамент земельных и имущественных отношений Приморского края. Распоряжение №26-p от 07 марта 2018 года. О резервировании земель под особо охраняемые природные территории регионального значения // Приморская газета. 2018. № 33 (1527). C. 66-72.

4. Ильченко О. Памятники природы в Приморье поставили на учет [Электронный ресурс] // Приморская газета. - Режим доступа: https://primgazeta.ru/news/ pamyatniki-prirody-v-primor-e-postavili-na-uchet-13-04-2019-04-14-44 (дата обращения: 13.04.2019).

5. Киселев А.Н., Крестов П.В., Скирина И.Ф. К созданию национального природного парка «Ливадийский хребет» // Ландшафтно-растительная поясность Ливадийского хребта (Южное Приморье). Владивосток: Дальнаука, 2001. С. 29-46.

6. Кудрявцева Е.П., Прокопенко С.В. Сохранить уникальный природный комплекс Ливадийского хребта // V Дальневосточная конференция по заповедному делу. Сборник материалов. 2001. С. 157-159.

7. Отчет о ходе реализации и оценке эффективности Государственной программы Приморского края «Развитие туризма в Приморском крае» на 2013-2021 годы за 2018 год [Электронный ресурс] // Администрация Приморского края. - Режим доступа: https://www.primorsky.ru/upload/medialibrary/4d6/4d64c25905c47fd967e0a446b 5c50732.pdf (дата обращения: 15.07.2019).

8. Перечень классифицированных маршрутов [Электронный ресурс] // Приморская федерация спортивного туризма. - Режим доступа: http://pfst.narod.ru/marsh.html (дата обращения: 15.07.2019). 
9. Положение о значке «Приморский Барс» [Электронный ресурс] // Приморская федерация спортивного туризма. - Режим доступа: http://pfst.narod.ru/bars.pdf (дата обращения: 15.07.2019).

10. Рекреация и туризм в Приморском Крае (ресурсно-экологические аспекты): Учебное пособие. Под ред. В.И. Преловского. Владивосток: ДВ филиал СПбГУП, 1998. $139 \mathrm{c}$.

11. Туристические кластеры «Пидан», «Изумрудное кольцо» и «Приморское кольцо» включили в ФЦП [Электронный ресурс] // PrimaMedia.ru. - Режим доступа: https://primamedia.ru/news/444728/ (дата обращения: 19.06.2015).

12. Туристическая нагрузка на Пидан превышена в 500 раз - ученые [Электронный ресурс] // vl.ru. - Режим доступа: https:/www.newsvl.ru/society/2017/11/10/164881/ (дата обращения: 10.11.2017).

13. Шабаев А.А., Сазыкин А.М. Туристическая посещаемость некоторых памятников природы Приморского края // FAR EAST TOURIST. 2013. №1. C. 20-24.

\section{References}

1. Bersenev Y. I. Osobo ohranyaemye prirodnye territorii Primorskogo kraya: sushchestvuyushchie i proektiruemye [Specially protected natural areas of Primorsky Krai: existing and projected]. Vladivostok, FEFU Publ., 2017. 202 p. (In Russian).

2. Gorit i ochen' sil'no: zhitelej Primor'ya bespokoit situaciya na Falaze. [It burns very much: the inhabitants of Primorye are concerned about the situation on the Falaza]. Available at: https://primamedia.ru/news/816223/ (accessed 27.05.2019).

3. Departament zemel'nyh i imushchestvennyh otnoshenij Primorskogo kraya. Rasporyazhenie №26-r ot 07 marta 2018 goda. O rezervirovanii zemel' pod osobo ohranyaemye prirodnye territorii regional'nogo znacheniya [Department of land and property relations of Primorsky Krai. Order No. 26-R of 07 March 2018. About reservation of lands under especially protected natural territories of regional value]. Primorskaya gazeta, 2018, no. 33 (1527), pp. 66-72. (In Russian).

4. Ilchenko O. Pamyatniki prirody v Primorye postavili na uchet [Nature monuments in Primorye put on record]. Available at: https://primgazeta.ru/news/pamyatniki-prirody-vprimor-e-postavili-na-uchet-13-04-2019-04-14-44 (accessed 13.04.2019).

5. Kiselev A.N., Krestov P.V., Skirina I.F. [To the creation of the national natural Park "Livadijskij ridge»] Landshaftno-rastitelnaya poyasnost Livadijskogo hrebta (YUzhnoe Primorye) [Landscape and plant belts of Livadijskij ridge (Southern Primorye)]. Vladivostok, Dalnauka Publ., 2001, pp. 29-46. (In Russian).

6. Kudryavceva E.P., Prokopenko S.V. Sohranit' unikal'nyj prirodnyj kompleks Livadijskogo hrebta [Preserve the unique natural complex of the Livadijskij ridge]. $V$ Dal'nevostochnaya konferenciya po zapovednomu delu. Sbornik materialov [V Far Eastern conference on wild nature protection. Collection of materials] 2001, pp. 157-159. (In Russian).

7. Otchet o hode realizacii $i$ ocenke effektivnosti Gosudarstvennoj programmy Primorskogo kraya «Razvitie turizma v Primorskom krae» na 2013-2021 gody za 2018 god [Report on the implementation and evaluation of the effectiveness of the State program of Primorsky Krai "Development of tourism in Primorsky Krai” in 2013-2021 for 2018]. 
Available at: https://www.primorsky.ru/upload/medialibrary/4d6/4d64c25905c47fd $967 \mathrm{e} 0 \mathrm{a}$ 446b5c50732.pdf (accessed 15.07.2019).

8. Perechen' klassificirovannyh marshrutov [A classified list of trails]. Available at: http://pfst.narod.ru/marsh.html (accessed 15.07.2019).

9. Polozheniye o znachke "Primorskiy Bars" [Statute of badge "Primorsky leopard"]. Available at: http://www.gfst-vl.ru/pb_official.html (accessed 15.07.2019).

10. Rekreaciya $i$ turizm v Primorskom Krae (resursno-ekologicheskie aspekty): Uchebnoe posobie (Pod red. V.I. Prelovskogo) [Recreation and tourism in the Primorsky Krai (resource and environmental aspects): textbook (ed. V.I. Prelovskij)]. Vladivostok, 1998. 139 p.

11. Turisticheskie klastery "Pidan", "Izumrudnoe kol'co" $i$ "Primorskoe kol'co" vklyuchili v FCP [Tourist clusters "Pidan", "Emerald ring" and "Primorsky ring" included in the FTP]. Available at: https://primamedia.ru/news/444728/ (accessed 19.06.2015).

12. Turisticheskaya nagruzka na Pidan prevyshena v 500 raz - uchenye. [Tourist load on Pidan exceeded 500 times - scientists.]. Available at: https://www.newsvl.ru/ society/2017/11/10/164881/ (accessed 10.11.2017).

13. Shabaev A.A., Sazykin A.M. Turisticheskaya poseshchaemost' nekotoryh pamyatnikov prirody Primorskogo kraya [Tourist traffic of some nature monuments of Primorsky Krai]. FAR EAST TOURIST, 2013, no. 1, pp. 20-24. (In Russian) 